\title{
EL DUQUE DE TERRANOVA EN LA CORTE DE FELIPE II ENTRE CONTIENDAS CORTESANAS, AVISOS PRUDENTES Y RELACIONES PELIGROSAS
}

\author{
Lina Scalisi \\ (Università degli Studi di Catania) \\ l.scalisi@unict.it
}

\section{RESUMEN}

Este trabajo se propone analizar el inicio de la carrera internacional de Carlos Aragón y Tagliavia, duque de Terranova, así como los acontecimientos, los personajes y las cuestiones que influyeron en la toma de decisiones. Nuestra atención se centra en los vínculos del duque con el círculo cortesano que en Madrid favoreció la elección, por parte del rey, del duque como embajador con plenos poderes en un Flandes sublevado. Nuestra intención última es contextualizar este episodio en el mecanismo general de elección de diplomáticos con cargos temporales, pero estratégicos, para las cuestiones más delicadas de la monarquía española; las extraordinarias oportunidades de éxito que comportó; el conflicto de fondo de una nobleza que lidiaba con la organización en el plano público de sus principales protagonistas; y, por último, esa "fluidez de representación" que permitió a algunos de estos personajes alternarse en diferentes cargos, haciendo alarde de habilidades, de relaciones cortesanas, alianzas políticas y apoyo familiar.

PALABRAS CLAVE: Terranova; Felipe II; Flandes; Sicilia; monarquía; corte; diplomacia

\section{THE DUKE OF TERRANOVA AT THE COURT OF PHILIP II BETWEEN COURTLY COMPETITION, PRUDENT ADVICE AND DANGEROUS RELATIONSHIPS}

\begin{abstract}
This paper aims to analyse the early international career of Carlos Aragón y Tagliavia, duke of Terranova, as well as the events, personalities and issues that influenced his decision-making. Our focus is on the duke's links with the courtly circle in Madrid, which favoured the king's choice of the duke as ambassador with full powers in the uprising Flanders. Our ultimate intention is to contextualise this episode within the general mechanism of election of diplomats who had temporary, but
\end{abstract}


strategic, positions for the most sensitive issues of the Spanish Monarchy; the extraordinary opportunities for success that it entailed; the underlying conflict of a nobility that was struggling with the public organisation of its main protagonists; and, finally, the "fluidity of representation" that allowed some of these characters to alternate in different positions, displaying their skills, establishing courtly relations, making political alliances and obtaining family support.

KEY WORDS: Terranova; Philip II; Flanders; Madrid; Sicily; monarchy; court; diplomacy.

Este trabajo se centra en el debut internacional de Carlos de Aragón y Tagliavia en el selecto grupo de "hombres del rey" enviados con plenos poderes a aquellos territorios de la monarquía con una situación compleja ${ }^{1}$. Nos situamos, pues, en el momento en que todavía no era virrey, el cargo más codiciado, ni embajador en las principales cortes europeas, sino ministro con plenos poderes dentro de la amplia situación diplomática, en el que un puesto de menor importancia le daba mayor libertad, aunque solo fuera por una flexibilidad que no se les concedía a los embajadores. Esta historia forma parte también de la renovada historiografía sobre el género que, hoy más que nunca, se configura como una herramienta útil para comprender las redes de poder de las clases dominantes europeas en la Edad Moderna a nivel transnacional y, al mismo tiempo, algunas cuestiones que van desde la historia política a la historia social del poder, pasando por la historia de las relaciones internacionales. Desde esta perspectiva, parece útil comenzar con el momento inicial de esta "aventura", es decir, cuando el Duque fue elegido para la empresa de Flandes con las difíciles negociaciones de la Dieta tan deseada por el Emperador Rodolfo a pesar de las dudas y titubeos de los rivales. Es una historia que forma parte de la biografía del personaje sobre la que trabajo desde hace tiempo, pero también es la punta del iceberg de la diplomacia en la Edad Moderna, tanto en los territorios de Europa como de fuera ${ }^{2}$ y cuyo estudio puede enriquecerse con la documentación de

${ }^{1}$ Este trabajo forma parte del proyecto de investigación interdisciplinar (linea 2 Piaceri) titulado GOST. Governare le emergenæe: politica, territorio, diritti (2020-21), y está relacionado con una reciente investigación mía, Lina Scalisi, Da Palermo a Colonia. Carlo Aragona Tagliavia e la questione delle Fiandre (15771580) (Roma: Viella, 2019), al que añadimos algunas conclusiones más sobre el papel de las élites a nivel trasnacional y de las oportunidades de los cargos diplomáticos temporales y al mismo tiempo estratégicos en las cuestiones más delicadas de la Monarquía hispánica.

${ }^{2}$ Renzo Sabbatini y Paola Volpini, eds., Sulla diplomaz̧a in età moderna: politica, economia, religione (Milán: Franco Angeli, 2011); Stefano Andretta, Lucien Bély, Alexander Koller y Géraud Poumarède, eds., Expérience et diplomatie. Savoirs, pratiques culturelles et action diplomatique à l'époque moderne (XVe-XVIIIe s.) (Roma: Viella, 2020). 
los grandes archivos privados, verdaderas minas de información de estos episodios a través de la correspondencia, un tipo de información que tiene la ventaja de tener un tono menos institucional ${ }^{3}$, más relacionado con las expectativas, dudas y dificultades a veces de los personajes implicados. En definitiva, un punto de vista centrado en los intereses privados y colectivos, la importancia del otorgamiento de favores y mercedes y las alianzas de una nobleza que lidiaba con la organización mayor del Estado, y con el plano público de sus principales protagonistas; y también con el deseo de mantener esa "fluidez de representación" dentro de esa élite restringida de personajes que podían alternarse en varios cargos, demostrando habilidades, red de relaciones, alianzas políticas y apoyos familiares ${ }^{4}$.

\section{LOS INICIOS}

¿Cuándo comienza la historia de Carlos de Aragón y Tagliavia, duque de Terranova, en el Madrid de Felipe II? En realidad, mucho antes de lo que atestiguan los documentos que describen su empresa como embajador en un Flandes sublevado encomendada por el soberano en la primavera-verano de 1578, cuando por fin había llegado a la capital española, tras un largo y dramático viaje por mar con naufragio incluido frente a las costas de Capri ${ }^{5}$.

Comenzó, de hecho, décadas antes durante las largas estancias del noble siciliano en las cortes del Emperador y del aún príncipe Felipe; cuando Madrid era solo una de las tantas ciudades de Castilla y la corte itinerante uno de los rasgos distintivos de los Austrias, que obligaba a la nobleza de los diferentes territorios a seguirles en largas y costosas empresas que eran, sin embargo, indispensables para construir la carrera y la fama ${ }^{6}$. En definitiva, Carlos de Aragón y Tagliavia llevaba tiempo

\footnotetext{
${ }^{3}$ En cuanto a las fuentes diplomáticas: Paola Volpini, “Ambasciatori, cerimoniali e informazione politica: il sistema diplomatico e le sue fonti", en Nel laboratorio della storia. Una guida alle fonti dell'età moderna, ed. Maria Pia Paoli (Roma: Viella, 2013), 237-264.

${ }^{4}$ Las prácticas de una élite cada vez más dinámica y proyectada hacia los contextos trasnacionales son el objeto de estudio de Bartolomé Yun Casalilla, Las redes del imperio. Élites sociales en la articulación de la Monarquía Hispánica (Madrid: Marcial Pons, 2009). El amplio abanico de estudios no nos permite dar una cuadro exhaustivo; citamos aquí solo Francisco Sánchez-Montes González, Julián José Lozano Navarro y Antonio Jiménez Estrella, eds., Familias, élites y redes de poder cosmopolitas de la Monarquía Hispánica en la edad moderna (siglos XVI-XVIII) (Granada: Editorial Comares, 2016); Adolfo Carrasco Martínez, Nobleza y los reinos: anatomía del poder en la Monarquía de España (siglos XVI-XVII) (Madrid: Iberoamericana Editorial, 2017); Giuseppe Cirillo, "L'Europa tra Asburgo e Borbone. Il ruolo delle élites transnazionali nella sperimentazione delle forme di governo", Nuova Rivista Storica CIV/II (2020): 771-784.

5 "La relación más conocida del ataque al galéon", en Relazione delle due galeotte della squadra di Sicilia, ed. Giovan Pietro Tornamira (Palermo: Carlo Adamo, 1674).

${ }^{6} \mathrm{La}$ bibliografía sobre el tema es muy amplia, pero sobre los primeros pasos en este campo de investigación hay que citar a José Martínez Millán, ed., Felipe II (1527-1598). Europa y la Monarquía Católica (Madrid: Parteluz, 1998); José Martínez Millán y Carlos Javier de Carlos Morales, eds., La configuración de
} 
preparándose para el debut internacional que lanzara su carrera más allá de las fronteras de la isla ${ }^{7}$. Heredero de un vasto estado patrimonial y de cargos de prestigio, había salido a menudo de sus feudos y participado en numerosas campañas militares y, sobre todo, se había apelado a sus protectores en la corte -desde Francisco Los Cobos a Diego de Espinosa, pasando por Granvela y Antonio Pérez- para que intercedieran ante el rey y éste le tuviera en cuenta.

En esto había sido instruido por su padre Juan, que había sido a su vez Presidente del Reino y Gran Almirante -este último cargo vinculado al linaje-, y bajo su tutela Carlos había perseguido su objetivo de mantener buenas relaciones con los virreyes que se habían turnado en la isla y de conseguir un consenso cada vez mayor. Una estrategia marcada por títulos como el de duque de Terranova obtenido en 1561 o el de príncipe de Castelvetrano en 1564, además del de Presidente del Reino en la época de García de Toledo, que fue renovado en 1571 cuando tuvo la oportunidad de demostrar sus habilidades políticas. Se trató de un segundo mandato largo que ocupó hasta 1577 gobernando solo, puesto que el rey no nombró un virrey eludiendo así la norma que prohibía a los autóctonos ejercer este cargo. Esta fue una elección afortunada, ya que Carlos supo estar a la altura de las expectativas ocupándose del ejército católico antes y después de Lepanto $^{8}$; de la terrible peste de 1575; y por último haciendo frente al asalto de Roma contra el privilegio de la Regia Monarquía, gracias al cual los virreyes de la isla conservaron plenos poderes en materia eclesiástica.

la Monarquía hispana (Valladolid: Junta de Castilla y León, 1998); José Martínez Millán, ed., La corte de Carlos V (Madrid: Sociedad Estatal para la conmemoración de los centenarios de Felipe II y Carlos V, 2000); Francesca Cantù y Maria Antonietta Visceglia, eds., L'Italia di Carlo V. Guerra, religione e politica nel primo Cinquecento (Roma: Viella, 2003).

${ }^{7}$ Nacido en Castelvetrano en 1521, hijo de Giovanni Tagliavia y de Antonia Concessa, hija de Carlos de Aragón, marqués de Ávola, fue heredero del vasto patrimonio feudal derivado de la unión de las familias Aragón y Tagliavia, cuyas posesiones se extendían por la mayor parte de la Sicilia central y occidental; y de cargos de prestigio, a menudo abandonados para participar en compañía de su padre en las campañas militares junto al Emperador en Alemania, África y los Países Bajos. Eran campañas interrumpidas sólo por breves estancias en Sicilia, como la de la primavera de 1544, cuando se casó con Margherita Ventimiglia, hija del marqués de Geraci, continuando con la política de alianzas matrimoniales útiles para la expansión política y patrimonial del linaje. Pero cuatro años más tarde, Carlos volvió a dejar la isla para acompañar al príncipe Felipe en su viaje a los futuros reinos de Europa, donde le llegó la noticia de la muerte de su padre. Fue entonces cuando comenzó realmente su carrera política en la isla, con el apoyo constante de Nicolas y Antoine Perrenot de Granvela y las alianzas con los principales grupos del reino. A partir de ahí, un éxito tras otro le llevaría, a finales de la década de 1570, primero al gobierno de Cataluña (1580-1582), luego al de Milán (1583-1592) y, finalmente, a Madrid en las filas del Consejo de Italia hasta su muerte en septiembre de 1599. Para una breve biografía de Terranova véase Lina Scalisi, "Terranova, Carlo Aragona Tagliavia, duca di”, Diz̨ionario Biografico degli Italiani, en línea: https://www.treccani.it/enciclopedia/terranova-carlo-aragona-tagliavia-ducadi \%28Dizionario-Biografico $\% 29 /$ (consultado el 5 de julio de 2021).

${ }^{8}$ Manuel Rivero Rodríguez, La batalla de Lepanto. Cruzada, Guerra Santa e identidad confesional (Madrid: Silex, 2008); Alessandro Barbero, Lepanto: la battaglia dei tre imperi (Roma-Bari: Laterza, 2010). 
Asimismo, cabe destacar que esta actitud no afectó al prestigio del que gozaba en la Santa Sede, gracias también a la protección del embajador español Juan de Zúñiga, que tranquilizó al pontífice sobre su devoción y su disposición a cumplir con las peticiones romanas en los futuros cargos en los que la monarquía delegara en él. Así que, aunque no faltaron críticas que le acusaban de una gestión del poder sin escrúpulos, la amplia red de relaciones y apoyos creada a lo largo del tiempo, su tendencia a resolver conflictos y el respaldo de la curia romana, le convirtieron en el candidato ideal para un cargo destinado a un personaje del agrado de los principales grupos cortesanos?

Así pues, la llegada de Terranova a Madrid en 1578 supuso su entrada en el grupo de ministros encargados de las tareas estratégicas en los vastos territorios de la monarquía ${ }^{10}$; un objetivo anhelado desde hacía tiempo y apoyado por quienes respaldaban su candidatura para el delicado puesto de embajador extraordinario en Colonia $^{11}$. Era, sin embargo, un nombramiento que irritaba a sus enemigos que llenaron la corte con cartas y testimonios contra su mal gobierno como Presidente del Reino, llegando a identificar su desventura por mar con la inexperiencia con la que ocuparía cualquier puesto futuro. Entre ellos se encontraba el virrey Marco Antonio Colonna, que aprovechó la ocasión para lanzar duras acusaciones a su adversario contra quien, en los meses anteriores, había escrito continuamente al secretario Mateo Vázquez de Leca, quejándose de cómo los aliados del duque le presionaban en Palermo para que entrara a su servicio ${ }^{12}$. En concreto, estaba el secretario de Terranova, Pietro Canales, que tenía lazos sólidos con los magistrados del reino y el apoyo en Madrid del

\footnotetext{
${ }^{9}$ Sobre la carrera de Terranova antes de salir de Sicilia véase Lina Scalisi, Magnus Siculus. La Sicilia tra impero e monarchia (1513-1578) (Roma-Bari: Laterza, 2012); y el reciente Lina Scalisi, "«Que pueda llegar a corte». Il duca di Terranova tra Lepanto e il futuro", en Ruy Gómez de Silva, príncipe di Éboli. Su tiempo y su contexto, eds. José Antonio Guillén Berrendero, Juan Hernández Franco y Esther Alegra Carvajal (Madrid: Iberoamericana, 2018), 285-302; Lina Scalisi, "Carlo d'Aragona e Antonio del Nobile. Difese militari, imprese economiche, vocazioni territoriali", en «Ser hechura de»: ingeniería, fidelidades y redes de poder en los siglos XVI y XVII, eds. Alicia Camara Munoz y Margarita Ana Vázquez Manassero (Madrid: Fundación Juanelo Turriano, 2019), 135-146.

${ }^{10}$ Francisco Sánchez-Montes González, Julián J. Lozano Navarro y Antonio Jiménez Estrella, eds., Familias, élites y redes de poder cosmopolitas de la Monarquía Hispánica en la edad moderna (siglos XVI-XVIII) (Granada: Editorial Comares, 2016).

11 Amplísima también la bibliografía sobre la cuestión de Flandes, remito a las síntesis presentes en Manuel Herrero Sánchez, "La Monarquía hispánica y la cuestión de Flandes”, en La Monarquía hispánica en tiempos del Quijote, ed. Porfirio Sanz Camañes (Madrid: Silex, 2005), 501-504; José Eloy Hortal Muñoz, Los asuntos de Flandes. Las relaciones entre las cortas de la Monarquía Hispánica y de los Paises Bajos durante el siglo XVI (Madrid: Universidad Autónoma de Madrid, 2011); Alicia Esteban Estríngana, "¿Renunciar a Flandes? La disyuntiva de separar o conservar los Países Bajos durante la primera mitad del reinado de Felipe II (1555/6-1579)", Cuadernos de Historia Moderna 43/1 (2018): 85-110.

${ }^{12}$ Sobre el virreinado de Colonna y su carrera: Nicoletta Bazzano, Marco Antonio Colonna (Roma: Salerno, 2003); Id., "L'ingresso di Marco Antonio Colonna a Palermo: apparati effimeri e tensioni politiche", en Hacer historia desde Simancas. Homenaje a José Luis Rodríguez de Diego, ed. Alberto Marcos Martín (Valladolid: Junta de Castilla y León, 2011), 97-106.
} 
secretario Gabriel de Zayas, y le respaldaba generando dudas sobre su correspondencia al Consejo de Italia porque estaba escrita en un estilo confuso y oscuro ${ }^{13}$. Para Colonna, se trataba de una clara intención de desprestigiarlo ante el Consejo donde estaban muchos de sus enemigos, y que devolvió al remitente con ironía, afirmando que escribía quizás en un castellano poco elegante, pero sin duda claro en objetivo e intenciones. Por lo tanto, hubo por ambas partes acusaciones muy graves ante las cuales Terranova reaccionó escribiendo al rey en varias ocasiones para quejarse afirmando que todo era fruto de la malicia; pero continuaron durante mucho tiempo, confirmando indirectamente las fuertes enemistades en la isla.

Sin embargo, no consiguieron ensombrecer el mérito que el Duque había ido adquiriendo ante los ojos del rey con su constante envío de recursos materiales necesarios para financiar la guerra en el Mediterráneo y en el Flandes sublevado ${ }^{14}$, donde el equilibrio que se había roto a mediados de los años 60 no parecía posible recomponer. De hecho, de poco había servido enviar allí al príncipe Juan de Austria, puesto que no había conseguido atraer el consenso de las élites sublevadas y se encontraba cada vez más aislado en un territorio que además estaba amenazado por los extranjeros.

Así que, a pesar de los enemigos, la carrera diplomática del poderoso noble comenzó con el apoyo de algunos ministros con los que había compartido alianzas y apoyos desde los años sesenta. Entre ellos destacaban Granvela y Juan de Zúñiga, en aquel momento embajador en Roma -quien había entrado desde hacía poco tiempo en las filas de la nobleza siciliana gracias a su matrimonio con Dorotea Barresi, una de las mayores herederas del reino ${ }^{15}$-, que se puso manos a la obra para atraer consenso entre los miembros del Consejo de Estado, a quienes el soberano había pedido una lista de nombres para la delicada embajada. Fue una decisión compleja que obligó al Consejo a reunirse varias veces para encontrar una solución consensuada y, antes de eso, para llegar a una resolución sobre los puntos del posible acuerdo.

De hecho, el consejo se ocupó de esta cuestión hasta mediados de julio y dio como resultado la afirmación de la supremacía real y la religión católica como puntos esenciales para el inicio de las negociaciones, junto con la petición de que España estuviera representada en la negociación por una persona autorizada y bien informada de la voluntad real. Para este cargo, se pensó en muchos candidatos, incluso no españoles, porque era opinión común que un nativo generaría tensiones. Pero si la emperatriz María abrió la lista por su respetabilidad y su posibilidad de intervenir a

\footnotetext{
${ }^{13}$ Instituto Valencia de don Juan (en adelante IVdJ), Entrada 6, Tomo II, doc. 28.

${ }^{14}$ Lina Scalisi, "«Que pueda llegar a corte»”, 285-303.

${ }^{15}$ Silvia D'Agata, A semejanza de Madrid. Reti di relazione tra Sicilia e Spagna alla corte di Giovanna d'Austria tra Cinque Seicento (en emprenta).
} 
diferentes niveles, su nombre se descartó enseguida por la convicción general de que tal cargo era más adecuado para un hombre. A continuación, estaba el cardenal Madruzzo, protector de Alemania y apreciado por el rey, pero menos por Gregorio XIII; el archiduque Fernando y el duque de Saboya, ambos pertenecientes al imperio, pero cercanos a España. Una lista prestigiosa de personas que, en realidad, tenía la función de conceder al Consejo más tiempo para encontrar soluciones funcionales al equilibrio político interno. Esto se deduce porque, tras estas primeras declaraciones, los miembros del Consejo se orientaron hacia los candidatos identificados en función de sus capacidades, provecho y lazos cortesanos. Entre ellos, estaba Terranova, considerado un hombre meticuloso que conocía Flandes y que era conocido desde que estuvo alli1 ${ }^{16}$.

Que el nombre del duque fuera también objeto de presión fuera del consejo lo confirma una carta del secretario Antonio Pérez a don Juan de Austria en la que le informa de que el rey aún no había decidido el nombre, pero que los Toledo apoyaban al cardenal de Burgos mientras que él se esforzaba para que se eligiera a una persona amiga del príncipe junto a los Vélez, con los que compartía el deseo de trabajar por su honor ${ }^{17}$. En cualquier caso, la carta reiteraba que el rey había decidido acogerse a la opinión del Consejo y que no actuaría de otro modo.

Mientras tanto, Carlos había llegado por fin a Madrid. En julio estaba de hecho en la corte y su presencia influyó en la decisión final, ya que cumplía una de las condiciones de la elección, que era, precisamente, la presencia en la corte para ser instruido y así evitar los peligros relacionados con el envío de correspondencia. También es seguro que en la elección influyó su fama, que no se había visto perjudicada por las recientes acusaciones; las largas décadas de servicio a la corona, los fuertes lazos con la nobleza siciliana y las sólidas amistades en la corte fueron fundamentales también cuando la muerte, a principios de los años setenta, de los principales ministros de los dominios

\footnotetext{
${ }^{16}$ Interesante fue la intervención del marqués de Almazán al poner la atención en los posibles embajadores imperiales expresando valoraciones sobre los principios para la elección, Archivo General de Simancas (en adelante AGS), Secretaría de Estado, leg. 2844, doc. 14.

17 Junto con varias noticias sobre otras importantes cuestiones: el dinero que llegaba de las Américas, el sueldo para las tropas, los nuevos cargos en territorio italiano, la tregua con el Turco: "A don Juan da Antonio Pérez”. Madrid, 22 de julio de 1578: AGS, Estado, leg. 577, doc. 133. En la carta hay también una referencia al Almirante de Castilla que Pérez consideraba hostil y que se esforzaba en desacreditarlo ante el rey. Este personaje es Luis Enríquez de Cabrera, tercer duque de Medina de Rioseco, almirante de Castilla, casado en 1587 con Vittoria Colonna (1558-1633) y propietario de varios dominios en Sicilia. Apreciado por el rey, en 1577 fue enviado como embajador extraordinario a la corte imperial para dar el pésame a Rodolfo por la muerte de su padre. En 1584 recibió el Toisón de Oro y murió en 1600.
} 
italianos ${ }^{18}$ provocó una renovación de la que también obtuvo beneficio ${ }^{19}$. A ello hay que añadir el favor de Antonio Pérez, con quien mantuvo una relación fiduciaria, lo que demuestra la complejidad de intereses materiales e ideales de los dirigentes de la monarquía divididos en grupos de alianzas inestables y constantemente redefinidas, a través del relevo de cargos, la negociación y el reajuste de las reglas en el espacio político. Esta relación maduró tras la muerte de Éboli, sin que ello afectara al vínculo con Granvela, para quien siguió defendiendo los intereses en Sicilia en un intercambio constante y recíproco de favores y mercedes que se desarrollaba a nivel local y supranacional.

En este contexto hay que entender, por tanto, la elección final de los ministros, en la que también influyó que el duque fuera considerado un personaje apreciado en Roma, aunque fuera sin excesos; apreciado también por Don Juan y por muchos ministros a los que solía enviar regalos y embajadas a través de sus valedores en la corte, ya que eran portadores de un significado simbólico más importante que el intercambio material, puesto que ponían de manifiesto relaciones políticas y, al mismo tiempo, creaban vínculos según las reglas de pertenencia y apariencia ${ }^{20}$. Nada inusual, por otro lado. La práctica del gobierno lo preveía; es más, lo consideraba un elemento esencial en el sistema más amplio del mecenazgo y la vida cortesana ${ }^{21}$, la participación y el reparto de poderes ${ }^{22}$, que indica cómo Carlos alcanzó el poder tanto en virtud de sus habilidades y alianzas, así como de un modus operandi compartido por todos aquellos

${ }^{18}$ Entre 1570 y 1571 murieron el virrey de Nápoles y de Sicilia -el marqués de Pescara y el duque de Alcalá respectivamente- y el duque de Alburquerque, gobernador de Milán, mientras sus sucesores el cardenal Granvela en Nápoles, Luis de Zúñiga y Requesens en Milán y Terranova en Sicilia- formaban parte de la misma alianza cercana a Espinosa: Manuel Rivero Rodríguez, Felipe II y el gobierno de Italia (Madrid: Sociedad Estatal para la Conmemoración de los Centenarios de Felipe II y Carlos V, 1998), 117.

19 Terranova esperaba desde hacía años un nuevo cargo sobre el que escribió varias veces al rey solicitando servirlo en los territorios en guerra: AGS, Estado, leg. 1133, docs. 2, 5 y 10.

${ }^{20}$ Eran sus valedores en Madrid el siciliano Mastretta, un delegado de negocios; Miguel Orban, avecindado en la calle San Jerónimo; y Juan Bayarte, al que había dado, en 1571, 3000 armas de damasco y treinta alfombras para repartir entre los diferentes personajes: British Library (en adelante BL), Additional, ms. 28396, fol. 290r.

${ }^{21}$ Francesco Benigno, L'ombra del re: ministri e lotta politica nella Spagna del Seicento (Venecia: Marsilio, 1992); Francesco Benigno, "Integration and Conflict in Spanish Italy", en Spain in Italy: Politics, Society, and Religion 1500-1700, eds. Thomas Jamres Dandelet, y John A. Marino (Leiden: Brill 2007), 23-44. Pero sobre estos temas remito al lector a la amplia bibliografía del Centro Europa delle Corti. Un caso interesante en Lina Scalisi, "I doni del principe. Storie di ambizioni, storie di nobiltà", en La storia e le immagini della storia. Prospettive, metodi, ricerche, eds. Matteo Provasi y Cecilia Vicentini (Roma: Viella, 2015), 159-180.

22 Natalie Zemon Davis, The Gift in Sixteenth-Century France (Oxford: Oxford University Press, 2000); Gadi Algazi, Valentin Groebner, Bernhard Jussen, eds., Negotiating the Gift Pre-Modern Figurations of Exchange (Göttingen: Vandenhoeck \& Ruprecht, 2003); Diana Carrio-Invernizzi, "Gift and Diplomacy in Seventeenth-Century Spanish Italy", The Historical Journal 51/4 (2008): 881-899. 
que estaban dispuestos a hacer grandes sacrificios, incluso económicos, para servir al rey. A esto hay que añadir el aprecio de Felipe II basado no solo en las relaciones de los ministros cercanos al duque, sino en el examen directo de la documentación relacionada con la administración de la isla y el testimonio oral de diferentes personas.

\section{EMBAJADOR CON PLENOS PODERES}

Pero el hecho de que fuera el preferido no se descubrió hasta principios de agosto en una carta de Felipe II a su hermano en la que le informaba de que había elegido a Terranova "por la gran estima que tenía de su persona", y que por tanto sería su interlocutor privilegiado ${ }^{23}$. De ese mismo día es la carta del nuncio apostólico al cardenal de Como, al mando de la diplomacia pontificia ${ }^{24}$, con el anuncio del nombramiento y las noticias sobre Madruzzo, propuesto por España como embajador imperial de Rodolfo II, en caso de que Orange le hubiera opuesto a él en el cargo de legado apostólico en un asunto que el nuncio consideraba en todo caso impracticable por la degradación del catolicismo en regiones invadidas por herejes de toda Europa. Por último, la noticia del viaje de Terranova de allí en unos diez días, tras una reunión para contarle "cosas de Flandes" de su conocimiento ${ }^{25}$.

${ }^{23}$ AGS, Estado, leg. 575, doc. 73. El rey añadió también que estaba preocupado por las posibles consecuencias de la llegada del conde palatino Juan Casimiro de Simmern, apoyado en el cargo de gobernador por Isabel I, y sugiere a su hermano que le comunique todo lo que suceda y de luchar contra el enemigo solo cuando la victoria estuviera asegurada.

24 Tolomeo Gallio nació en Cernobbio en el seno de una familia patricia en 1526. Brillante en sus estudios, tuvo primero la oportunidad de frecuentar a Paolo Giovio como copista hasta 1549; luego al cardenal Antonino Trivulzio, en cuya intensa vida diplomática participó y, a la muerte de éste, al cardenal Giovanni Angelo Medici. Y fue el propio Médicis, elegido al trono papal en 1559 con el nombre de Pío IV, quien le confió la coordinación de la correspondencia diplomática de la Santa Sede y alentó su rápida carrera eclesiástica. Rodeado de la amistad de importantes personalidades, pero también de la hostilidad de muchos exponentes de la curia, a la muerte de Pío IV se retiró a su diócesis de Manfredonia, donde vivió durante algún tiempo intentando aplicar los decretos tridentinos. Pero su deseo de no chocar con las autoridades locales y españolas le llevó, al cabo de poco tiempo, a retirarse a su villa de Piperno y luego a Roma. Tras la muerte de Pío V y la elección de Gregorio XIII, en la que participó, fue nombrado jefe de la secretaría diplomática y su autoridad pasó a ser indiscutible. Para sus relaciones con Gregorio, los escenarios políticos y diplomáticos en los que se movió Galio y los acontecimientos con el futuro Papa Sixto V, además de Giampiero Brunelli, Gallio, Tolomeo, en Dizionario biografico degli Italiani, https://www.treccani.it/enciclopedia/tolomeo-gallio (Dizionario-Biografico)/ (consultado el 5 de julio de 2021), véase Per Olof von Törne, Ptolémée Gallio, cardinal de Côme. Étude sur la cour de Rome, sur la secrétairerie pontificale et sur la politique des papes au XV Te siècle (París: A. Picard, 1907).

25 "Carta del Nuncio a Madrid, cardinal Sega, al cardinal de Como. Madrid, 2 de agosto de 1578", en Nuntiaturberichte aus Deutschland nebst ergänzenden Aktenstücken: Erste Abteilung 1572-1585, ed. Joseph Hansen, t. II (Gotha, 1892), 211-213. En cuanto al duque de Alençon, Sega refiriendo los inútiles intentos de obtener una audiencia por parte del Nuncio Fabio Mirto Frangipani, arzobispo de Nazareth - y de como este lo intentería de nuevo junto al embajador de Venecia, Giovanni Micheli, insistía en que el rey de Francia no estaba de acuerdo con el hermano y que esperaba que aquello evitase el choque con Francia, lo cual complicaría todavía más la situación diplomático-militar. Sobre la mediación de 
$\mathrm{Ni}$ que decir tiene que, tras el nombramiento real, la atención hacia Terranova fue constante. Al mando de una difícil empresa, proyectado hacia los vértices de la diplomacia europea, todos sus movimientos eran observados. Ocurrió sobre todo en los meses siguientes porque se vio obligado a decidir a menudo en función de la información y de las difíciles posibilidades que ofrecía el contexto, valiéndose de la red de corresponsales a través de la cual buscaba apoyo, mediaciones e información para mantener el control de una situación dominada por la incertidumbre. Pero en las primeras semanas, cuando aún estaba en España, no fue consciente de ello, ya que dedicó su tiempo a reunirse con los ministros de Madrid y a estudiar las instrucciones que había recibido de Felipe II, asegurando que afrontaría cualquier situación imprevista con templanza, astucia y prudencia.

En realidad, muchas de las cosas que el rey y Pérez le dijeron a Carlos, se las comunicaron verbalmente. Así lo indican las instrucciones que en varios lugares utilizan la fórmula "como de palabra", revelando las audiencias privadas concedidas al Duque para prepararlo frente a los riesgos de la empresa. El examen de estas instrucciones revela la jerarquía de los deseos de la monarquía -la preservación de la religión católica, obediencia a España y el alejamiento del archiduque Matías de esos territorios- a partir de los que iniciar las negociaciones, rechazando cualquier otra condescendencia con las religiones reformadas. Sin embargo, no era la versión oficial de las Instrucciones la que tenía que guiar la acción del Duque, sino la versión secreta que trataba el contenido de las primeras de forma diferente ${ }^{26}$. En primer lugar, se trataban los límites en los que el duque podía moverse y que, en el caso de la religión, debían ser inamovibles, ya que nada podía alterarse en ese sentido. Para ello, era necesario actuar con inteligencia, buscando espacios de negociación en los asuntos relacionados con la liga de las provincias protestantes y las funciones de los estados generales. Si el objetivo final era la restauración de la época de Carlos V, suprimiendo los cambios posteriores que habían conducido a la soberanía progresiva de los estados generales y había desvirtuado las jurisdicciones y poderes del gobernador, era necesario destituir a Orange, considerado como el origen de todos los males, y ofrecerle los cargos a su hijo; la restitución de los bienes feudales y muebles y una ingente suma de dinero. Pero debían quedar fuera del acuerdo los cargos asignados de los estados generales, y el de Almirante del mar, con el que había luchado contra las flotas españolas.

Mirto : Ivan Cloulas, ed., I. Correspondance du Nonce en France Anselmo Dandino (1578-1581) (Rome-Paris: Presses de l’Université Grégorienne y Éditions E. de Boccard, 1970).

26 "Instrucion secreta que se dio al duque de Terranova para la Junta dela pacification de los Paises Baxos”. Madrid, 8 de septiembre de 1578: AGS, Secretaría de Estado, leg. 2844, doc. 4. 
Tampoco Terranova debía dar crédito a las pretensiones de los candidatos extranjeros, porque si Don Juan no era del agrado de esos pueblos, solo el rey podía decidir quién lo sustituiría y nadie podía obtener nada en ese sentido. Además, era necesario evitar que los estados recurrieran de nuevo al emperador o a los príncipes alemanes. Por lo tanto, la negociación debía encaminarse a la conquista del consenso de los electores y de los ministros incluso a través de la práctica de otorgar mercedes y favores, realizada con el cuidado y el estilo que le eran propios y para la cual se le habían asignado grandes sumas de dinero, y se habían previsto más si encontraba la manera de hacer lo mismo con los diputados de los estados. La última instrucción se refería, en cambio, al secreto de las mismas que nadie debía conocer y por lo que pagaría, evidente demostración de la prudencia con la que Felipe II miraba tanto a sus enemigos como a sus aliados fuera de España.

En agosto comenzó así la embajada de Terranova, sobre la que él mismo escribió a Scipione di Castro, por entonces en Roma en la corte de Gregorio XIII ${ }^{27}$, a los pocos días de su nombramiento, para pedirle su opinión sobre un asunto tan importante para la cristiandad. Castro respondió a esta petición en poco tiempo, con un texto emitido después de varios borradores, algunos de los cuales estaban llenos de sus correcciones manuscritas, como puede verse en el Fondo Boncompagni. El texto, enviado a finales de octubre, presenta elementos de notable interés, ya que las prioridades indicadas por Castro eran similares a las contenidas en las instrucciones reales que el letrado demostró conocer, probablemente porque había sido informado por Terranova y/o porque en los círculos de la corte romana se discutían estas cuestiones fundamentales por parte de personajes que compartían los mismos deseos que España.

Pero lo que hay que destacar aquí es el hecho de que su opinión se centrara en la necesidad de revisar la composición de Gante, acusada de debilitar la religión católica y la obediencia, del mismo modo que las instrucciones secretas de Felipe II. En definitiva, un claro indicio del nivel de información del que gozaba Castro en la corte

\footnotetext{
${ }^{27}$ La estancia de Castro en la corte romana fue gracias a la protección concedida por el hijo del papa, Giacomo Boncompagni, y del mismo pontífice que concedió numerosos cargos relacionados con obras de ingeniería disimulando así su cargo como consejero político. Tal discreción derivaba de las muchas y discutidas vicisitudes del personaje - para muchos un fanfarrón protagonista de escándalos internacionales, perseguido por la Inquisición- lo que sin embargo no obstaculizó una proficua producción de escritos sobre las cuestiones más importantes de su época, incluido Flandes, sobre lo cual había escritos al papa dos memoriales entre el otoño de 1577 y la primavera de 1578, cfr. Roberto Zapperi, "Castro, Scipio di", Diz̨ionario biográfico degli Italiani, en línea: https://www.treccani.it/enciclop edia/scipio-di-castro \%28Dizionario-Biografico\%29/ (consultado el 5 de julio de 2021). Empero, sobre Boncompagni cfr. Umberto Coldagelli, "Boncompagni, Giacomo", Dizionario biografico degli italiani, en línea: https://www.treccani.it/enciclopedia/giacomo-boncompagni (Dizionario-Biografico) (consultado el 5 de julio de 2021).
} 
romana y de la confianza del duque. Por el contrario, Castro no las tenía todas consigo por lo que se refería a la obediencia que exigía Felipe II como "vuelta al pasado", pues si todos los pueblos obedecían por amor o por miedo, en el caso de los flamencos, ambos sentimientos habían sido sustituidos por el odio a España, lo que les llevó a perpetrar continuas ofensas, y cualquiera de ellas podría haber provocado una guerra. $\mathrm{Y}$ en este escenario, la decisión del rey de querer la paz fue peligrosa porque anulaba los esfuerzos bélicos españoles en territorios dispuestos a abandonar la monarquía ${ }^{28}$.

Castro prefería, en cambio, subrayar que toda paz estable surgía de una poderosa guerra y, por tanto, que la obediencia solo se podía recuperar con el tiempo y la labor de un gobernador hábil. Tampoco se mostraba muy optimista sobre el cumplimiento de los pactos, para lo que confiaba más en las plazas fuertes de la frontera con Francia y en el mantenimiento del statu quo en el Ducado de Luxemburgo, ya que era casi imposible domesticar a los flamencos si no se les trataba como se hace «con i cavalli, difficili et aspri di bocca, a' qual non si mette mai freno se non tinto di mele, da che il procedere di morsi violenti, ci ha fatto conoscere che sempre s'annega chi nuota nel sangue» ${ }^{29}$.

No fueron agüeros favorables y, desde luego, no tranquilizaron a Terranova que, a finales de septiembre, con una reducida corte, cargado de bienes y enseres, abandonó Madrid, llevando consigo entre sus pertenencias personales y con el debido cuidado los numerosos despachos que le habían confiado el rey y Pérez. El mismo rey dio noticia de ello a su hermano en Flandes, asegurándole que había comprendido la situación en aquellos territorios por sus cartas de septiembre, e informándole de la próxima llegada del duque y del comienzo de la empresa ${ }^{30}$. Se había dado así el último paso y el príncipe, que en los últimos meses había intentado disuadir a su hermano sobre la paz, tuvo que rendirse ante la nueva decisión.

\footnotetext{
28 «Quanto alle ragioni particolari, doversi conoscere la bontà [...] del Re con i suoi sudditi di Fiandre, e la particolare affetione ch'e' porta alli suoi stati patrimoniali da quella spetie di guerra che hoggi fa, vedendosi, che vuol più presto portare, che adoprar l'armi contra di loro, nel modo, che potrebbe fare, da che non mancherebbero a si gran Principe forze maggiori da far la guerra da vero quando si risolvesse a voler. Sapersi la debolezza estrema delli stati, e le difficultà grandi con le quali han poste bene queste genti, stancando gli amici, esaurendo se stessi, e spogliando le chiese»: Biblioteca Apostolica Vaticana (en adelante BAV), Boncompagni D-10, c. 375.

${ }^{29}$ «Con los caballos, difíciles y ásperos de boca, a los que nunca se les pone freno si no teñido de manzanas, ya que el proceder de los mordiscos violentos, nos ha indicado que quien nada en sangre siempre se ahoga» [Traducción propia]: Ibídem, c. 401.

30 "El rey al príncipe don Juan". Madrid, 10 de octubre de 1578: AGS, Estado, leg. 575, doc. 192.
} 


\section{CONCLUSIONES}

Los hechos expuestos hasta aquí van más allá del plano individual de Carlos de Aragón y Tagliavia, y se inscriben plenamente en la dinámica de una élite a nivel transnacional que se movió en los espacios políticos de la monarquía española, uniendo los territorios de forma efectiva en una especie de codiciada migración diplomática que involucró a muchas familias y fue funcional a los proyectos dinásticos de proyección supralocal. Esto es lo que ocurrió con Terranova que a finales de los años setenta iniciaría una prestigiosa carrera internacional que, tras Flandes, le llevaría a gobernar primero el virreinato de Cataluña, luego el gobierno del Milanesado y, finalmente, un sólido puesto en el reducido grupo de ministros de Felipe II. Pero está igualmente claro que la obtención del nombramiento fue posible gracias a una alianza transnacional que le consideró la persona más adecuada para verificar la dudosa mediación de Rodolfo y limitar los riesgos de una posible apertura a la tolerancia religiosa. El hecho de que detrás de este nombramiento estuviera la lucha entre los grupos de la corte sobre cuál era la mejor línea política para beneficiarse de lo que estaba ocurriendo en el campo de batalla y, al mismo tiempo, de la crisis interna de los propios insurgentes, no disminuye su importancia. Tampoco el hecho de que demostrara cómo lo que se decidía en las cortes era después objeto de una continua remodelación por parte de los protagonistas políticos y su capacidad para unir los intereses generales con los particulares, más triviales, explotando las habilidades, las redes de comunicación, las alianzas políticas y los lazos familiares. 


\section{REFERENCIAS BIBLIOGRÁFICAS}

Algazi, Gadi; Groebner, Valentin y Jussen, Bernhard, eds., Negotiating the Gift Pre-Modern Figurations of Exchange (Göttingen: Vandenhoeck \& Ruprecht, 2003).

Andretta, Stefano; Bély, Lucien; Koller, Alexander y Poumarède, Géraud, eds., Expérience et diplomatie. Savoirs, pratiques culturelles et action diplomatique à l'époque moderne (XVe-XVIIIe s.) (Roma: Viella, 2020).

Barbero, Alessandro, Lepanto: la battaglia dei tre imperi (Roma-Bari: Laterza, 2010).

Bazzano, Nicoletta, Marco Antonio Colonna (Roma: Salerno, 2003).

—, "L'ingresso di Marco Antonio Colonna a Palermo: apparati effimeri e tensioni politiche", en Hacer historia desde Simancas. Homenaje a José Luis Rodríguez. de Diego, ed. Alberto Marcos Martín (Valladolid: Junta de Castilla y León, 2011), 97-106.

Benigno, Francesco, L'ombra del re: ministri e lotta politica nella Spagna del Seicento (Venecia: Marsilio, 1992).

—, "Integration and Conflict in Spanish Italy", en Spain in Italy: Politics, Society, and Religion 1500-1700, eds. Thomas Jamres Dandelet, y John A. Marino (Leiden: Brill 2007), 23-44.

Brunelli, Giampiero, Gallio, Tolomeo, en Dizionario biografico degli Italiani, https://www.treccani.it/enciclopedia/tolomeo-gallio (DizionarioBiografico)/ (consultado el 5 de julio de 2021).

Cantù, Francesca y Visceglia, Maria Antonietta, eds., L'Italia di Carlo V. Guerra, religione e politica nel primo Cinquecento (Roma: Viella, 2003).

Carrasco Martínez, Adolfo, Nobleza y los reinos: anatomía del poder en la Monarquía de España (siglos XVI-XVII) (Madrid: Iberoamericana Editorial Vervuert, 2017).

Carrio-Invernizzi, Diana, "Gift and Diplomacy in Seventeenth-Century Spanish Italy", The Historical Journal 51/4 (2008): 881-899.

Cirillo, Giuseppe, “L’Europa tra Asburgo e Borbone. Il ruolo delle élites transnazionali nella sperimentazione delle forme di governo", Nuova Rivista Storica 104/2 (2020): 771-784.

Cloulas, Ivan, ed., I. Correspondance du Nonce en France Anselmo Dandino (1578-1581) (Rome-Paris: Presses de l'Université Grégorienne y Éditions E. de Boccard, 1970). 
Coldagelli, Umberto, "Boncompagni, Giacomo", Diæ̌ionario biografico degli italiani, en línea: $\quad$ https://www.treccani.it/enciclopedia/giacomoboncompagni_(Dizionario-Biografico) (consultado el 5 de julio de 2021).

D'Agata, Silvia, A semejanza de Madrid. Reti di relazione tra Sicilia e Spagna alla corte di Giovanna d'Austria tra Cinque Seicento (en emprenta).

Davis, Natalie Zemon, The Gift in Sixteenth-Century France (Oxford: Oxford University Press, 2000).

Eloy Hortal Muñoz, José, Los asuntos de Flandes. Las relaciones entre las cortas de la Monarquía Hispánica y de los Paises Bajos durante el siglo XVI (Madrid: Universidad Autónoma de Madrid, 2011).

Esteban Estríngana, Alicia, “¿Renunciar a Flandes? La disyuntiva de separar o conservar los Países Bajos durante la primera mitad del reinado de Felipe II (1555/6-1579)", Cuadernos de Historia Moderna 43/1 (2018): 85-110.

Hansen, Joseph, ed., Nuntiaturberichte aus Deutschland nebst ergänzenden Aktenstücken: Erste Abteilung 1572-1585 (Gotha, 1892).

Herrero Sánchez, Manuel, "La Monarquía hispánica y la cuestión de Flandes”, en La Monarquía hispánica en tiempos del Quijote, ed. Porfirio Sanz Camañes (Madrid: Silex, 2005), 501-504.

Yun Casalilla, Bartolomé, ed., Las redes del imperio. Élites sociales en la articulación de la Monarquía Hispánica (Madrid: Marcial Pons Historia, 2009).

Martínez Millán, José, ed., Felipe II (1527-1598). Europa y la Monarquía Católica (Madrid: Parteluz, 1998).

- La corte de Carlos V (Madrid: Sociedad Estatal para la conmemoración de los centenarios de Felipe II y Carlos V, 2000).

Martínez Millán, José y de Carlos Morales, Carlos Javier, eds., La configuración de la Monarquía bispana (Valladolid: Junta de Castilla y León, 1998).

Rivero Rodríguez, Manuel, La batalla de Lepanto. Cruzada, Guerra Santa e identidad confesional (Madrid: Silex, 2008).

Sabbatini, Renzo y Volpini, Paola, eds., Sulla diplomažia in età moderna: politica, economia, religione (Milano: Franco Angeli, 2011). 
Scalisi, Lina, Da Palermo a Colonia. Carlo Aragona Tagliavia e la questione delle Fiandre (15771580) (Roma: Viella, 2019).

—, "Terranova, Carlo Aragona Tagliavia, duca di", Diz̧ionario Biografico degli Italiani, en línea: $\quad$ https://www.treccani.it/enciclopedia/terranova-carlo-aragonatagliavia-duca-di \%28Dizionario-Biografico \%29/ (consultado el 5 de julio de 2021).

—, "I doni del principe. Storie di ambizioni, storie di nobiltà", en La storia e le immagini della storia. Prospettive, metodi, ricerche, eds. Matteo Provasi y Cecilia Vicentini (Roma: Viella, 2015), 159-180.

—, "Carlo d'Aragona e Antonio del Nobile. Difese militari, imprese economiche, vocazioni territoriali", en «Ser hechura de»: ingeniería, fidelidades y redes de poder en los siglos XVI y XVII, eds. Alicia Camara Munoz y Margarita Ana Vázquez Manassero (Madrid: Fundación Juanelo Turriano, 2019), 135-146.

—, "Magnus Siculus". La Sicilia tra impero e monarchia (1513-1578) (Roma-Bari: Laterza, 2012).

—, "«Que pueda llegar a corte». Il duca di Terranova tra Lepanto e il futuro”, en Ruy Gómez de Silva, príncipe di Éboli. Su tiempo y su contexto, eds. José Antonio Guillén Berrendero, Juan Hernández Franco y Esther Alegra Carvajal (Madrid: Iberoamericana, 2018), 285-302.

Volpini, Paola, "Ambasciatori, cerimoniali e informazione politica: il sistema diplomatico e le sue fonti”, en Nel laboratorio della storia. Una guida alle fonti dell'età moderna, ed. Maria Pia Paoli (Roma, Viella, 2013), 237-264.

Von Törne, Per Olof, Ptolémée Gallio, cardinal de Côme. Étude sur la cour de Rome, sur la secrétairerie pontificale et sur la politique des papes au XVIe siècle (París: A. Picard, 1907).

Sánchez-Montes González, Francisco; Lozano Navarro, Julián José y Jiménez Estrella, Antonio, eds., Familias, élites y redes de poder cosmopolitas de la Monarquía Hispánica en la edad moderna (siglos XVI-XVIII) (Granada: Editorial Comares, 2016).

Zapperi, Roberto, "Castro, Scipio di”, Dizionario biografico degli Italiani, en línea: https://www.treccani.it/enciclopedia/scipio-di-castro \%28DizionarioBiografico\%29/ (consultado el 5 de julio de 2021). 
Recibido: 30 de abril de 2021

Aceptado: 19 de julio de 2021 